\title{
Shepherd Or Servant: Centralization And Decentralization In Information Technology Governance
}

Roger Alan Pick, University of Missouri - Kansas City, USA

\begin{abstract}
Information Technology (IT) governance deals with how decision-making authority concerning IT is distributed across the firm. Based upon that distribution of authority, different behaviors and consequent decisions can be observed. A fundamental question is the degree of centralization and decentralization of that authority and the ability to standardize. Standardization often has benefits, but there can be negative repercussions if the standard does not take into account localized needs. The dominant governance mechanism has changed as technology and available tradeoffs have changed.
\end{abstract}

Keywords: Centralization; Decentralization; IT Governance; Standardization

\section{INTRODUCTION}

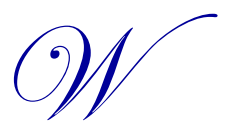

ho makes the decisions about Information Technology (IT) at your firm? Who sets the rules? Who is in charge? Who should make which decisions? Who initiates? Who approves? Who monitors and reviews? Is the IT group a shepherd guiding a flock of non-IT professionals safely through a dangerous virtual landscape? Or is it a servant obeying the orders of its non-IT masters? Or something in-between? Which is better and when? This article will try to answer some of these questions.

Information Technology (IT) governance concerns how an organization makes decisions about information technology and information technology organizations. It is not about what the decisions are, but rather it is about who has the right to make a decision, has input to a decision, or will be held accountable for the decision (Weill, 2004 , p. 3). There are a variety of ways that IT governance can be set up, and there is not one single way that is always best. In other words, there does not seem to be a single best practice for making IT decisions. Furthermore, there are no standards for IT governance and no body of knowledge concerning best practices (Nolan and McFarlan, 2005). Each approach has certain strengths and weaknesses, and the correct approach for a given organization depends upon many factors. "Researchers are unanimous that a universal best IT governance structure does not exist," (Brown and Grant, 2005, p. 703). The goal for an organization is to find the particular combination of strengths and weaknesses that serves it best at the time. And what is best at a given time will vary from organization to organization based in part on differences in firms' environments (Ribbers et al, 2002). Moreover, there is a range of differing yet successful governance mechanisms in such IT applications as knowledge management (Schroder $e t$ $a l$, 2012). In the remainder of this article, the term "governance" will be used as a shorthand for "information technology governance."

Some authors on governance focus on accounting and auditing issues (Ferguson et al, 2012), the use of IT to provide better governance across the entire organization (Estrada, 2010; Williams and Seaman, 2014), or the impact of governance maturity on organizational performance (Lazic et al, 2011), but the focus of this article will be on the leadership of the Information Systems (IS)/IT functional area, centralization versus decentralization, and the likely results from different governance forms. 
The maturity of data communications technologies today gives organizations an unprecedented level of flexibility in structuring governance. When data communications technology was more costly, less capable, and less reliable than it is today, certain IT governance mechanisms were imposed on organizations by the limitations of technology. For example, in the 1960s many large corporations had highly decentralized governance mechanisms because they had to locate processing, databases, development personnel, and support personnel at each location where data was created and used. In those circumstances, there was little ability to make informed decisions when they affected multiple locations. Each decision at each location was isolated. Today, we can easily move data to where it is needed.

\section{SIX GOVERNANCE ARCHETYPES}

In a framework that I find useful, Weill (2004) classifies IT governance into six categories: business monarchy, IT monarchy, feudal, federal, IT duopoly, and anarchy. In Weill's framework, each type of IT decision might be governed in one of six general ways. The business monarchy is characterized by a single, centralized decision-maker, and that decision maker is a business executive. The IT monarchy is similar in that there is a single decision maker, but in that case the decision maker is an executive from IT. Under a feudal system, IT decisions are decentralized to the leaders of various business units. In an IT duopoly, IT decisions are centralized to a committee including both IT executives and one other group such as C-level executives or business unit executives. Under a federal system, IT decisions are centralized to a committee including C-level executives and one other group such as IT executives or business unit executives. These six categories do not partition the space of possibilities. For example, the federal system and duopoly can overlap in a governance committee including three types of decisionmakers: IT executives, C-level executives, and business unit leaders. These governance committees are often called "steering committees." The balance of power between IT and various business units can be fine-tuned by balancing the membership of the committee between IT executives and business unit executives. Finally, anarchy allows every individual user to make their own uncoordinated and decentralized decisions.

Each of these six general types can be further subdivided. For example, a firm might use an IT monarchy to make decisions about the overall IT infrastructure but a federal system to make decisions about priorities among proposed IS applications.

There are circumstances in which each of these governance types has merits. The structure, strategy, and processes for IT need to match or align with those of the rest of the organization (Henderson \& Venkatraman, 1999). Under the varying technological and business environments of the past seven decades, we find situations in which each type is common. Each governance type can also be characterized by the types of behaviors it encourages. People respond to incentives, and they will be more responsive to individuals in a position to reward them than to others. The nature of the IT leaders and decision makers will affect the responsiveness of IT staff: if the leaders are from a business unit, that business unit will experience responsive service. Do we want leadership of IT to come from the user groups or from the functional area (Kranz \& Pick, 1989)?

A feudal system is perhaps the hardest to argue for today. Under the feudal system, each business unit makes its own IT decisions, sets its own priorities, and acquires whatever IT its budget allows. It is an example of extreme decentralization, and in a pure implementation of this scheme, the independent decisions being made at each unit results in duplication of effort, needless proliferation of solutions, and inability to gain economies of scale. And yet, if a firm sees itself strategically as a collection of non-interacting units that may be sold at any time, the decoupling provided by feudalism will prevent information technology from inhibiting the pursuit of that strategy.

In an organization whose IT function is governed according to the business monarchy, the IT function reports to a single business executive. This works well when the goal is to support the monarch's agenda and priorities. There was a time when the IT function at many organizations was mostly about automating accounting and bookkeeping functions. In such a time, having the IT organization report to the controller might make a great deal of sense. At many firms today, the most important IT applications under development are in such areas as social networking and customer engagement. Having the IT organization report to a chief marketing officer may help the firm in giving these applications the priority they deserve. 
Some companies have established a board-level IT governance committee. Examples include Mellon Financial, Novell, Home Depot, Procter \& Gamble, Wal-Mart, and FedEx (Nolan and McFarlan, 2005). Raising IT decisions and oversight to the corporate board generally is a response to concerns about regulatory compliance, especially Sarbannes-Oxley, or it can happen in an organization in which IT is in a strategic mode: both the current success and future success of the firm depends on excellent execution of its production IT systems and on excellent deployment of coming applications in the future (Nolan and McFarlan, 2005).

\section{HISTORY}

Consider the history of IT governance in terms of a prototypical Fortune 500 corporation over the past 60 years. This prototypical history is inspired by a similar discussion in King (1983) and extends it through another thirty years.

1950s

In the 1950s, information technology processing power was very expensive. Major uses of computers were often to replace "pink collar" computers, people (mostly women) performing a computationally-intensive clerical job. By today's standards, electronic computers were expensive, but they were less expensive than the human computers they replaced. Being expensive, processing was limited to a small number of high-value computationintensive applications. Many of these applications were engineering-oriented. It was fairly common for a corporation at the time to have a single computer, located and managed at a single location. Thus, information technology began as centralized function by default because there was one computer in a single location, and the people who managed the technology were those who were immediately working with it. It was a time of monarchy.

1960s

As the cost of processors and storage relative to labor fell, more applications such as accounting were justified as the applications became more cost-effective. This expanded range of applications in turn often justified purchase of additional computers. Many corporations would have a computer at their headquarters and an additional computer at each major branch. Networking between these computers was nonexistent, so these computers did not exchange data in the same way they do it today. If data were exchanged between locations at all, uploading and downloading were accomplished by the physical transport of magnetic media (usually magnetic tapes) among branches and headquarters. The first family of instruction-compatible computers did not come out until the IBM 360 was announced in 1965, so often each machine owned by a given corporation was different, and there was no compatibility among software. Most decisions about computing were isolated, and governance was highly decentralized. Decisions about priorities were made at each physical location with little or no consultation among locations. It was a feudal time.

1970s

Point to point data communications became common in the 1970s. It became possible for previously isolated computer installations to start to exchange data with one another via direct connections. This capability started to enable new organizational forms. Headquarters could be more directive because they would have data about events at remote locations. Coordinated, centralized decisions about hardware purchasing started to make sense because we wanted the hardware at different locations to be able to exchange data with each other. There were several competing data communications standards at the time, so that if you wanted to share data between locations, you had to have picked compatible hardware up front. The technology of the time started to give rise to centralization of governance.

1980s

The rise of desktop PCs in the 1980s resulted in a new set of isolated hardware. Initially, these PCs were not accompanied by a support organization. Decentralization of this component of the IT infrastructure was the rule of the day, at least at first. Anyone who had a budget large enough to purchase a PC could do so, and often they did. 
So, during this era, decisions about mainframes or other large computers, the devices that connected to them, and the applications that ran on them were often made centrally. And with the PCs, governance could be characterized as anarchy.

1990s

Client/server computing gave rise to a new form of centralized computing. Coordination became necessary again so that devices at different locations could work with each other. PCs were decentralized, but they had to work with more centrally-managed servers. But extreme centralization need not prevail. Servers could support individual branch offices, individual functional areas, individual departments, or even individual work-groups. So, individual business units were able to make the decisions they thought best for their unit without thought about the needs of the organization as a whole. Internetworking technologies became affordable, enabling connection of networks that used incompatible protocols. Thus, governance was often feudal, with each fief making decisions in its own best interests.

2000s

The turn of the millennium is characterized by maturity of web-enabled applications. Although some of these are internal, such as a variety of human resources processes, the larger value comes from Internet-enabled value chain activities (Barua et al, 2004). Governance must deal with the face that the organization presents to supplier-side parts of the value chain as well as the customer-side. In order to prevent confusion on the parts of suppliers and customers, there should be uniformity to what is presented. This implies a centralized style of governance. Depending upon whether the supplier-side or the customer-side is more strategic, a business monarchy rules from either a supply chain manager or a marketing manager or even an oligarchy represented by both areas. This decade is also influenced by the passage of the Sarbanes-Oxley Act in 2002, with mandates for greater fiscal accountability. This also implies a centralized style of governance for accounting and financial applications and data.

2010s

The second decade of the third millennium is characterized by "Bring Your Own Device" and by "cloud computing." Due to the rise of portable consumer devices, including wireless phones and tablets with sufficient power to do corporate computing, devices designed for the consumer rather than the business market are being used in the business world. By allowing employees to use their personally-owned and chosen technologies in the workplace, a host of support, compatibility, and security issues arise (Wang et al, 2014). Corporate networks, applications, and data are forced to work with a variety of employee-chosen devices. Support organizations must be able to respond to requests for help from people using devices that the organization is unfamiliar with. If the workplace tries to restrict employees' choice concerning, for example, what type of device they might use to check email, employees may ignore the rules or push back in other ways. A new type of anarchy has arisen.

Cloud computing is also a phenomenon of the current decade. Provision of computing resources over the cloud involves "on-demand access to virtualized IT resources that are housed outside your own data center, shared by others, simple to use, paid for by subscription, and accessed over the web." (Armbrust et al, 2010). Similar to the case with PCs in the 1980s, the ease of entry this technology enables computing to be purchased by anyone with a corporate credit card. Such a purchaser may not think about how his/her decisions fit in with a broader set of organizational policies (privacy and security being especially problematic) and initiatives. So, we have in the present decade a second technology that lends itself to feudal and anarchistic decisions.

\section{CENTRALIZATION VERSUS DECENTRALIZATION}

The question of centralization versus decentralization of IT organization includes governance, and the answer can be a continuum from allocating all IT resources to a single unit that provides the entire organization with IT services to allocating all IT resources to various business units that use those resources to provide for their own needs without considering other units (Gordon \& Gordon, 2000). In an early discussion of the issue, (King, 1983) divides the centralization and decentralization into three separate dimensions: physical location, function, and 
control. Physical location concerns where devices are placed; the maturity and low cost of communications technologies have made this decision relatively unimportant. Function concerns where IT-using activities take place. Control is the dimension of interest to a discussion of governance. If control is centralized, top management retains decision rights. If control is decentralized, discretion is given to lower-level managers. In the former case, the organization retains the ability to establish uniformity. In the latter case, decisions are made by those with the greatest local knowledge of their situations. Decentralization allows greater flexibility and may enable greater responsiveness to business needs. When the business strategy is to allow flexibility and effectiveness in meeting varying business demands, the best governance strategy would be feudal. The choice of IT centralization versus decentralization may be affected by the overall organizational design of the firm in that IT will match the style of the overall organization. And the capabilities afforded by IT in turn affect the ability to centralize or decentralize the organization's overall design (Nault, 1998).

Cash et al (1992, p. 277) summarizes the forces that pressure the organization toward centralization or toward decentralization. Centralization provides a more professional operation, efficient use of staff, efficient use of equipment capacity, multiple access to common data, assurance of data standards, availability of specialized staff, richer professional career paths, and a match for those organizations that are managed in a centralized style. Decentralization provides greater user control, responsiveness to users, simpler control, easier access to data, better fit with needs of each branch, and a match for those organizations that are managed in a decentralized style. To the extent that technical knowledge concerning IT is limited and in rare supply, it may be better to concentrate the decision-making authority in the hands of those with that knowledge.

We have seen in recent years the rise of newer forces pushing the organization towards centralization. These include recognition of vulnerability to security breaches, recognition of need to plan for business continuity, and needs to both comply and document compliance with government regulations such as Sarbannes-Oxley, HIPPA, and FERPA.

Centralization may take more than one possible form. For example, centralization looks very different with leadership provided by an IT monarch as opposed to a business monarch. A business monarch's functional area will tend to dominate IT use, and that could be highly suitable. This behavior arises because people respond to incentives and will want to please the individuals who will be reviewing their performance. In the 1950s, when engineering applications were strategic to the firm, a business monarch from engineering may have been the best IT leader. In the 1960s, a business monarch from the accounting world may have been a good choice. Today, when marketing applications and customer engagement via social media are strategic, giving IT decision-making authority to a chief marketing officer is often the right choice.

One interesting approach to decentralization is to give decision-making authority to low-level managers, but increase their responsibility for their choices by charging their budget for the cost of what they choose, even if their services are provided internally (Whinston, 1964). Pricing can also be used to set priorities among different groups for whose needs will be served sooner and who will have to wait (Pick and Whinston, 1989).

\section{Standardization}

The advantages of centralized styles of governance include the ability to adopt a standardized IT architecture across the organization. In a decentralized style such as feudalism or anarchy, it is not possible to enforce or even choose a single standard. Generally in IT, a choice of a standard will reduce costs and make IT management and support easier. The main advantages of standards are that uniformity reduces complexity and enables scale. In terms of help desk and support organizations, greater uniformity allows for fewer different situations sets of documentation to be maintained and less training needs. In terms of servers and other hardware, uniformity means that if you've seen one, you've seen them all. Uniformity results in staff in different locations or areas of the organization being inherently cross-trained. Uniformity means that you are buying more each of a smaller number of alternatives, thereby giving you more leverage with your suppliers. By standardizing on a smaller number of service suppliers, you reduce the number of supplier contracts to be negotiated. Hardware uniformity reduces the number of spare parts you must carry in inventory. 
In general, a major disadvantage of standardization is that groups whose needs are poorly met by the standard are going to be unhappy with it or even ineffective. Decisions may be made by individuals or committees far-removed from the operating needs of user groups. Low-level managers will have greater knowledge of their local situation, and they may be able to make technological choices that best match their circumstances. On the other hand, if functional knowledge about IT is limited, then those low-level managers may make poor decisions in spite of their greater localized knowledge.

\section{Power Balance}

The choice of governance mechanism can affect the balance of power between IT professionals and users. Because they control access to useful technologies, IT professionals have intrinsic power over their users (Markus and Bjorn-Andersen, 1987). An IT monarchy would further cement the professionals' power. By putting business people in charge, the anarchy, feudal, or business monarchy approaches shift the balance of power back towards the users. An IT duopoly or federal system would tend to provide an intermediate result. When priorities are set and decisions made by a committee, changing the relative numbers of general managers versus IT managers allows finetuning the relative power between the two groups. The makeup of an IT governance committee and the inclusion or non-inclusion of various stakeholder groups affects the outcomes. The politics of conflict resolution and forming coalitions within the committee becomes part of the effective governance mechanism (Peterson, 2004). Prasad et al (2010) surveyed 216 firms and found that IT governance via steering committee positively affected IT-related capabilities, which in turn positively affected internal process-level performance.

\section{CONCLUSION}

The goal of this article was to provide an updated general overview of IT governance options available to the organization and to take account of how the appropriate choice shifts in response to changes in technology, organizational goals, and regulatory climate. As technology evolves, new capabilities enable new arrangements of decision-making power and new technologies provide new challenges in rationalizing usage. Top management needs to think through what is the current and near-future strategy of the organization, the behaviors that they want to encourage, and the kinds of freedom they want to allow. Based upon this kind of reflection, the appropriate governance mechanisms for the organization and its times are chosen.

\section{AUTHOR INFORMATION}

Dr. Roger Alan Pick is Professor of Management Information Systems at the Henry W. Bloch School of Management at the University of Missouri - Kansas City (UMKC) where he has been since 1993. He has taught over 3700 students at Purdue University, University of Wisconsin - Madison, University of Cincinnati, Louisiana Tech University, and UMKC. His primary teaching assignment is management of information technology. His research interests are in decision support systems, model management, information technology economics, and information systems governance and leadership issues. He has published over 50 peer-reviewed or edited articles on those topics. He earned his doctorate from the Krannert Graduate School of Management at Purdue University in 1984.

\section{REFERENCES}

Armbrust, M., Fox, A., Griffith, R., Joseph, A. D., Katz, R., Konwinski, A., Lee, G., Patterson, D, Rabkin, A, Stoica, I., \& Zaharia, M. (2010). A view of cloud computing. Communications of the ACM, 53(4), 50-58.

Barua, A., Konana, P., Whinston, A. B., \& Yin, F. (2004). An empirical investigation of net-enabled business value. MIS Quarterly, 28(4), 585-620.

Brown, A., \& Grant, G. (2005). Framing the frameworks: A review of IT governance research. Communications of the Association for Information Systems (Volume 15, 2005), 696-712.

Cash Jr, J. I., McKenney, J. L., McFarlan, F. W., \& Applegate, L. M. (1992).Corporate information systems management: text and cases. McGraw-Hill.

Estrada, C. F. (2010). Aligning information technology within the framework of corporate governance to increase corporate value in Mexico. International Journal of Management \& Information Systems (IJMIS), 14(2). 
Ferguson, C., Green, P., Vaswani, R., \& Wu, G. H. (2012). Determinants of effective information technology governance. International Journal of Auditing.

Gordon, J. R., \& Gordon, S. R. (2000). Structuring the interaction between IT and business units. Information Systems Management, 17(1), 7-16.

Henderson, J. C., \& Venkatraman, N. (1993). Strategic alignment: Leveraging information technology for transforming organizations. IBM Systems Journal,32(1), 4-16.

King, J. L. (1983). Centralized versus decentralized computing: organizational considerations and management options. ACM Computing Surveys (CSUR),15(4), 319-349.

Kranz, R., \& Pick, R. A. (1989). Is Data-Processing a Shepherd or a Servant. Journal of Systems Management, 40(10), 15.

Lazic, M., Heinzl, A., \& Neff, A. (2011). "IT Governance Impact Model: How mature IT Governance affects Business Performance," Proceedings of JAIS Theory Development Workshop. Sprouts: Working Papers on Information Systems, 11(147). http://sprouts.aisnet.org/11-147, accessed on 5 November 2014.

Markus, M. L., \& Bjørn-Andersen, N. (1987). Power over users: its exercise by system professionals. Communications of the ACM, 30(6), 498-504.

Nault, B. R. (1998). Information technology and organization design: Locating decisions and information. Management Science, 44(10), 1321-1335.

Nolan, R., \& McFarlan, F. W. (2005). Information technology and the board of directors. Harvard business review, 83(10), 96.

Peterson, R. (2004). Crafting information technology governance. Information Systems Management, 21(4), 7-22.

Pick, R. A., \& Whinston, A. B. (1989). A computer charging mechanism for revealing user preferences within a large organization. Journal of management information systems, 6(1), 87-100.

Prasad, A., Heales, J., \& Green, P. (2010). A capabilities-based approach to obtaining a deeper understanding of information technology governance effectiveness: Evidence from IT steering committees. International Journal of Accounting Information Systems, 11(3), 214-232.

Ribbers, P. M., Peterson, R. R., \& Parker, M. M. (2002, January). Designing information technology governance processes: diagnosing contemporary practices and competing theories. In System Sciences, 2002. HICSS. Proceedings of the 35th Annual Hawaii International Conference on (pp. 3143-3154).

Schroeder, A., Pauleen, D., \& Huff, S. (2012). KM governance: the mechanisms for guiding and controlling KM programs. Journal of Knowledge Management, 16(1), 3-21.

Wang, Y., Wei, J., \& Vangury, K. (2014, January). Bring your own device security issues and challenges. In Consumer Communications and Networking Conference (CCNC), 2014 IEEE 11th (pp. 80-85).

Weill, P. (2004). Don't just lead, govern: How top-performing firms govern IT.MIS Quarterly Executive, $3(1), 1-17$.

Whinston, A. (1964). Price Guides in Decentralized Organization. in New Perspectives in Organizational Research, New York: John Wiley and Sons.

Williams, J. J., \& Seaman, A. E. (2014). Determinants Of Ethical Climate In The Firm: The Role Of Governance Control Systems And Environmental Uncertainty. International Journal of Management \& Information Systems (IJMIS), 18(4), 241-260. 


\section{NOTES}

